\title{
STEREO-PHOTOGRAMMETRIC MEASUREMENT OF SPATIO-TEMPORAL VELOCITY FIELDS AT LANGE GLACIER, KING GEORGE ISLAND
}

\author{
Ellen Schwalbe ${ }^{1}$, Robert Koschitzki ${ }^{1}$, Erling Johnson ${ }^{3}$, Diego Fernando Mojica Moncada ${ }^{3,4}$, Benjamin Schröter ${ }^{2}$, Carlos $_{\text {Cardenas }}{ }^{3}$, \\ Gino Casassa ${ }^{3}$, Hans-Gerd Maas ${ }^{1}$ \\ ${ }^{1}$ Institute of Photogrammetry and Remote Sensing, Technische Universitat Dresden, Germany \\ ${ }^{2}$ Institute of Cartography, Technische Universität Dresden, Germany \\ ${ }^{3}$ Gaia Antarctica Research Center, Universidad de Magallanes, Chile \\ ${ }^{4}$ Centro de Investigaciones Oceanográficas e Hidrográficas del Caribe, Dirección General Marítima, Colombia
}

(hans-gerd.maas@tu-dresden.de)

KEY WORDS: Stereo image sequence tracking, glaciology

\begin{abstract}
:
A network consisting of six cameras was set up on both sides of Lange Glacier on King George Island, Antarctica, for a period of two years to monitor changes in the glacier's motion behaviour. The cameras were observing spatio-temporal glacier surface velocity vector fields as well as the position of the glacier front. Velocity field information was obtained from image sequences by applying subpixel accuracy photogrammetric image sequence analysis techniques. Georeferencing in a superordinate coordinate system was performed via integrated photogrammetric-geodetic network adjustment. As a result, velocity fields were determined with maximum glacier surface velocities in the order of 1.5 meter per day. The results of terrestrial camera image sequence processing can be used as validation and calibration reference for satellite image based glacier velocity dynamics calculations. Moreover, the very high temporal resolution of the image sequences taken at 20 minute time intervals can also be used to analyse highly dynamic processes.
\end{abstract}

\section{INTRODUCTION}

Global warming has resulted in significant worldwide ice mass loss of glaciers, ice caps and ice sheets in recent decades (Vaughan et al., 2013). In Antarctica ice loss is particularly concentrated in the Amundsen Sea region and in the Antarctic Peninsula (Williams et al., 2014), which has been subject to enhanced atmospheric warming and partly as well also oceanic warming in recent decades, as a result of direct anthropogenic forcing enhanced by positive feedbacks (Mayewski et al., 2013). The Antarctic Peninsula and adjacent sub-antarctic islands are especially sensitive to climate changes due to their location within the southern westerly belt, which is affected by atmospheric and oceanic mid-latitude changes. Large glacier retreat and in some areas also ice velocity increase has been reported for the Antarctic Peninsula (Cook et al., 2005; Vaughan et al., 2013), including King George Island (Simões et al., 1999; da Rosa et al., 2015). The uncertainty on the mass balance is still very high, in particular for calving glaciers, which is the main contribution to ice loss in Antarctica and in many tidewater and freshwater glaciers. In fact, the equilibrium line altitude (ELA) is located at or very close to sea level in Antarctica, so that surface melting is normally a minor component of the total ablation. The work presented here is part of a project, which aims at calculating the mass balance on the Arctowski Icefield on the north-western part of King George Island (KGI) using field data from Lange Glacier and Bellingshausen Dome in combination with imaging radar (SAR) data from satellite missions.

A set of six cameras has been installed at Lange glacier, taking images at regular time intervals in order to determine glacier surface velocity vector fields by photogrammetric image sequence tracking techniques and to observe the position of the glacier front. The camera configuration was geo-referenced via a geodetic-photogrammetric network in order to allow for a comparison of results between different techniques.

There is a lack of calibrating data obtained from ground truthing that can help to validate and improve satellite derived studies on glacier dynamic (e.g. calving flux, retreat, etc). One objective of the terrestrial photogrammetric measurement was the generation of such data. For that purpose, glacier velocities and frontal line position of the terminus were determined from the terrestrial image sequences. Besides their $\mathrm{cal} / \mathrm{val}$ function, the photogrammetric image sequence can be used to analyse high dynamic processes, such as detailed characterization of calving events, including surface vs. submarine calving.

\section{FIELD SITE}

The measurements were taken at the frontal part of Lange Glacier (Fig. 1, 62 ${ }^{\circ} 07^{\prime} \mathrm{S}, 58^{\circ} 30^{\prime}$ 'W).

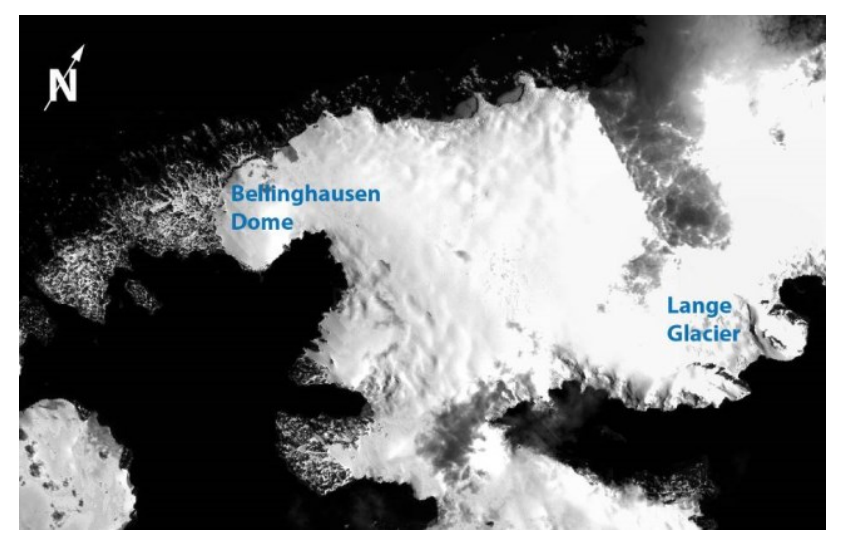

Figure 1: Western part of King George Island and field site for ground measurements (source: LIMA Mosaic - USGS) 
A total of six SLR cameras has been set up along the ridges at both sides of Lange Glacier (Fig. 2) for a total measurement period of two years. The cameras were placed in weather-proof housings and equipped with a power supply supported by solar panels and buffer batteries (Fig. 3). The cameras for glacier velocity measurement were operated at 20 minute time intervals, those for glacier front position determination at one hour intervals.

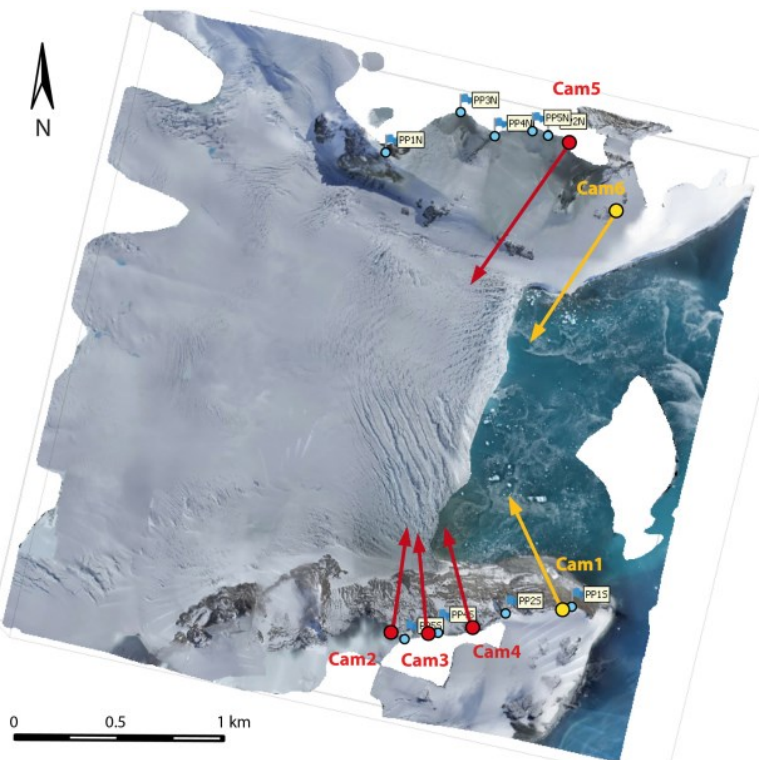

Figure 2: Camera network at Lange Glacier with cameras observing the glacier (red) and the glacier front (yellow); geodetic control points are marked in blue

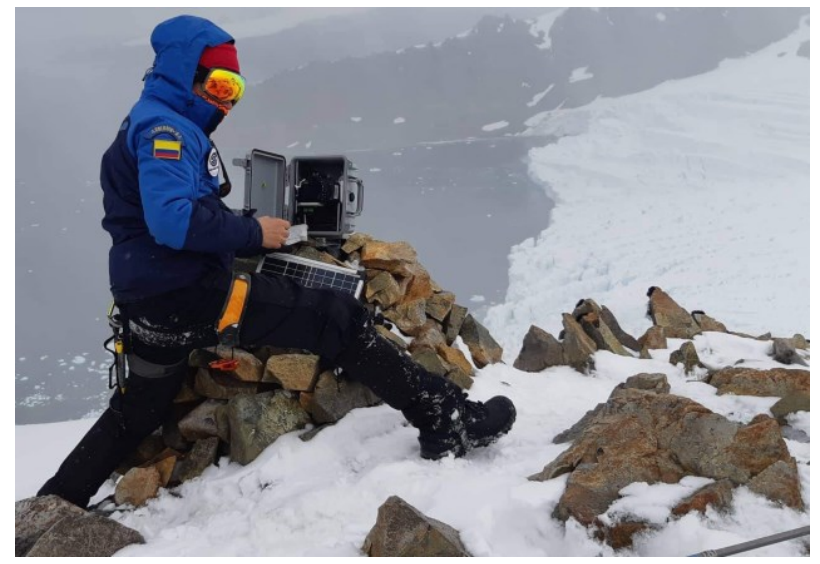

Figure 3: Camera installation at Lange Glacier

\section{CAMERA NETWORK GEOREFERENCING}

The orientation parameters of all cameras were determined by photogrammetric bundle adjustment supported by geodetic control points measured by GNSS techniques in an approach similar to the one presented in (Schwalbe/Maas, 2018) and (Maas et al., 2013). Images strips were taken at the northern and southern ridge with 289/152 images. 9 geodetic control points were measured by GNSS and used for datum definition. The six positions of the cameras taking image sequences were also determined by GNSS. The cameras were pre-calibrated by selfcalibrating bundle adjustment before being installed. Several fiducials (visible in Fig. 5) were placed on stable rock in the image foreground in order to be able to detect wind-induced camera motions and to compensate for them.

The photogrammetric image block was also used to create a surface height model of the glacier, which was later used as a reference surface in the process of scaling the measured trajectories from image space to metric object space (see Schwalbe/Maas, 2018).

\section{IMAGE SEQUENCE PROCESSING}

The results presented here are based on the first year of data acquisition of the four cameras observing the glacier for spatiotemporal velocity field determination. As one can see from Fig. 4 , the image sequences contain many gaps, mainly due to adverse weather conditions and power shortage during the winter. Dark or foggy images, which are not useful for glacier surface feature tracking, were sorted out automatically in a procedure analyzing image brightness and contrast criteria.

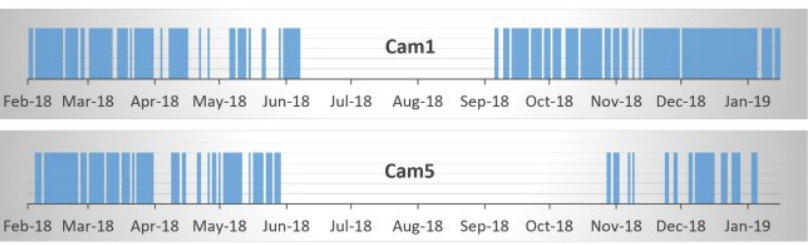

Figure 4: Overview on useful images of two cameras on the north and south ridge over one year of data acquisition

The velocity information was obtained from the images classified as useful for processing by subpixel accuracy leastsquares feature tracking using our approach as described in detail in (Schwalbe/Maas, 2018). The velocity vectors were corrected for wind-induced camera motion effects by tracking the stable fiducials in the image foreground. The vector fields were georeferenced via the results of the photogrammetricgeodetic network adjustment. The developed software tool is freely available and can be downloaded at www.tudresden.de/geo/emt.

\section{RESULTS}

Figure 5 shows an example of a velocity field obtained from processing one week of image data from one camera. Figure 6 shows a merged velocity field based on data obtained from processing image sequences from all four cameras observing the glacier surfaces. Maximum velocities in the order of 1.5 meter per day could be determined.

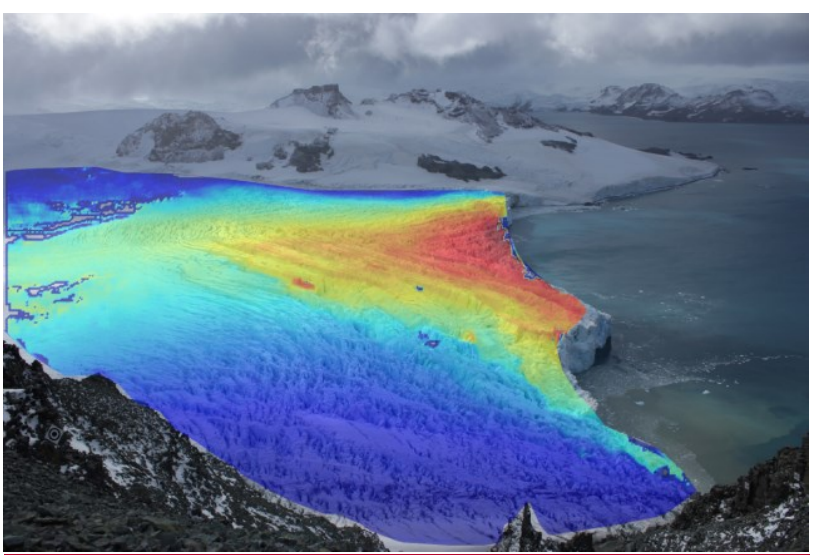

Figure 5: Velocity field obtained from one camera (color code $\rightarrow$ Fig. 


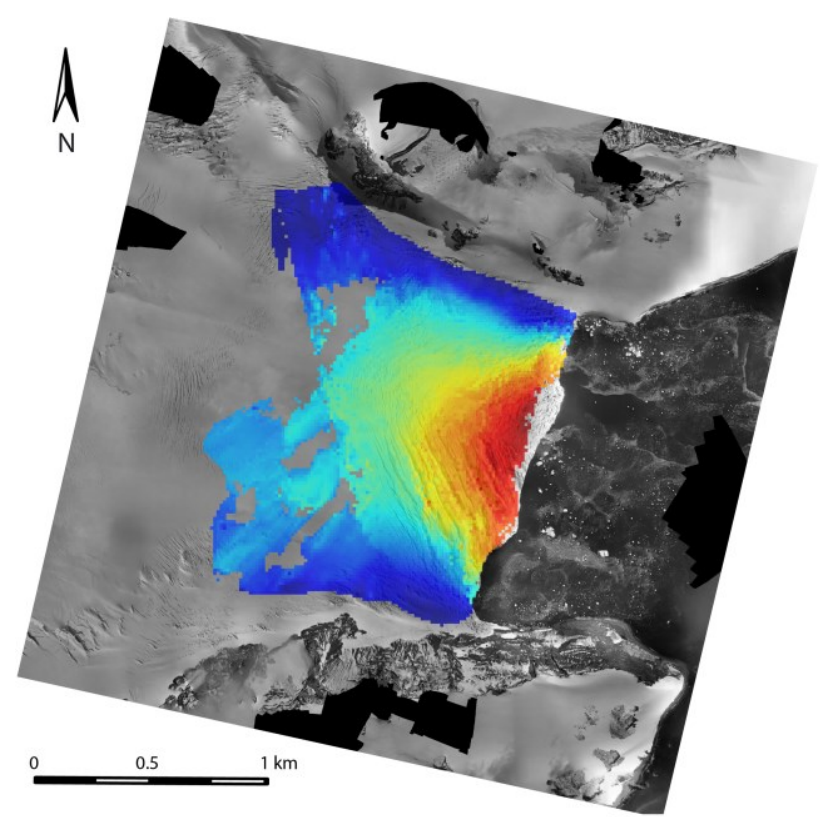

$28.03 .2018-08.04 .2018$

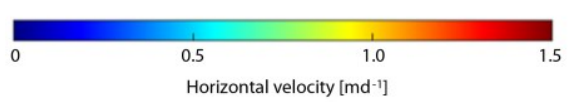

Figure 6: Color-coded merged velocity field obtained from both sides of the glacier

Figure 7 shows a surface velocity field determined from Sentinel 1-B satellite radar image data (Cardenas et al., 2020; Johnson et al., 2020), which was obtained through the 'offset tracking' processing module from SNAP $($, an open access software from the European Space Agency (ESA). The results are in good coincidence with the validation data determined from the terrestrial cameras.

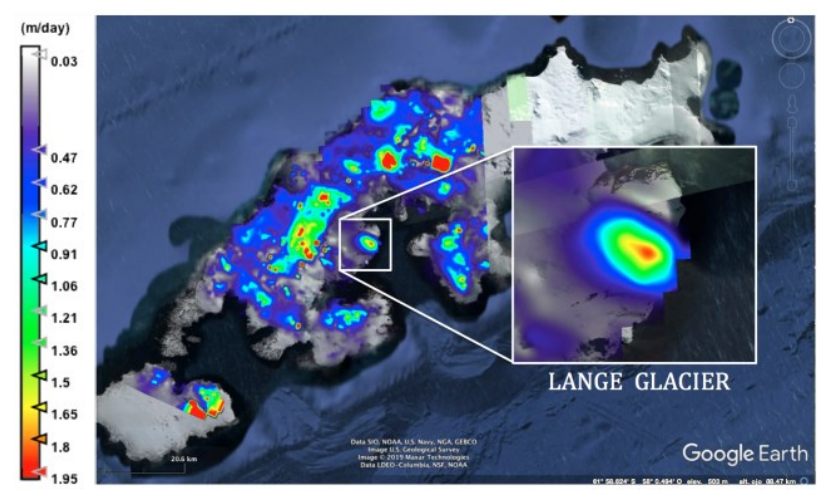

Figure 7: Color-coded merged velocity field obtained from both sides of the glacier (Cardenas et al., 2020)

\section{ACKNOWLEDGEMENT}

The work presented in this paper was supported by the Chilean INACH. The development of the basic techniques for glacier image sequence feature tracking was funded by the German Research Foundation (DFG). The software development was further supported by the program "support the best" of the Technische Universität Dresden. We would also like to thank the personnel of the INACH Base Profesor Julio Escudero and the Machu Picchu Antarctic Scientific Station of Peru for their support during the campaigns on King George Island.

\section{REFERENCES}

Cárdenas, C., Casassa, G., Aguilar, X., Mojica, D., Brondi, F., 2020: From Space to Earth: physical and biological impacts from glacier dynamic by mean of Remote Sensing at Almirantazgo Bay, Antarctica. IEEE Latin American GRSS \& ISPRS Remote Sensing Conference (LAGIRS)

Cook, A. J., Fox, A. J., Vaughan, D. G., Ferrigno, J. G. (2005): Retreating glacier fronts on the Antarctic Peninsula over the past half-century. In: Science, 308, pp. 541-544

Da Rosa, K. K., Vieira, R., Fernandez, G., Mendes, C. W., Velho, L. F., Simões, J. C.(2015): Recent changes in the Wanda Glacier, King George Island, Antarctica. In: Pesquisas em Geociências, 42(2), pp. 187-196

Johnson, E., Floricioiu, D., Schwalbe, E., Koschitzki, R., Maas, H.-G., Cardenas, C., Cassasa, G., 2020: Calving dynamics derived from satellite SAR data in support of mass balance estimations in Lange Glacier, Antarctica. IEEE Latin American GRSS \& ISPRS Remote Sensing Conference (LAGIRS)

Maas, H.-G., Casassa, G., Schneider, D., Schwalbe, E., Wendt, A. (2013): Photogrammetric Techniques for the Determination of Spatio-temporal Velocity Fields at Glaciar San Rafael, Chile. Photogrammetric Engineering and Remote Sensing, Vol. 79, No. 3, pp. 299-306

Mayewski, P. A., Maasch, K. A., Dixon, D., Sneed, S. B., Oglesby, R., Korotkikh, E., Potocki, M., Grigholm, B., Kreutz, K., Kurbatov, A. V. \& others (2013): West Antarctica's sensitivity to natural and human-forced climate change over the Holocene. In: Journal of Quaternary Science, 28(1), pp. 40-48

Schwalbe, E.; Maas, H.-G. (2018): The determination of highresolution spatio-temporal glacier motion fields from time-lapse sequences. In: Journal of Earth Surface Dynamics 5 (2018), pp. 861-879

Simões, J. C., Bremer, U. F., Aquino, F.E., Ferron, F.A. (1999): Morphology and variations of glacial drainage basins in the King George Island ice field, Antarctica. In: Annals of Glaciology, 29, pp. 220-224

Vaughan, D. G., Comiso, J. C., Allison, I., Carrasco, J., Kaser, G., Kwok, R., Mote, P., Murray, T., Paul, F., Ren, J., Rignot, E., Solomina, O., Steffen K., Zhang, T. (2013): Observations: Cryosphere. In: Climate Change 2013, pp.317-382

Williams, S. D. P., Moore, P., King, M. A., Whitehouse, P. L. (2014). Revisiting GRACE Antarctic ice mass trends and accelerations considering autocorrelation. In: Earth and Planetary Science Letters, 385, pp. 12-21 